\title{
OPCIONES DE MEDIACIÓN PARA RESOLVER DISPUTAS COMERCIALES EN CHINA
}

\author{
MEDIATION OPTIONS FOR RESOLVING COMMERCIAL DISPUTES IN \\ CHINA
}

\author{
Peter C.H. Chan ${ }^{*}$
}

\begin{abstract}
RESUMEN: Este artículo analiza las alternativas de que dispone una empresa extranjera para resolver sus disputas comerciales en China. La falta de independencia judicial y la tendencia de los tribunales populares hacia el proteccionismo de las empresas locales, vuelven preferible acudir a las Soluciones Alternativas de Confictos. El arbitraje en CIETAC cumple con los estándares internacionales. Pero si una de las partes no cumple voluntariamente el laudo, surgen problemas al intentar el cumplimiento forzado ante los tribunales chinos porque estos pueden rechazar la ejecución. La mediación aparece como la mejor opción en China. Los acuerdos alcanzados en una mediación comercial suelen ser cumplidos volutariamente, esquivando las dificultades de la ejecución judicial. Además, el Centro de Mediación y la mediación durante un arbitraje en CIETAC (med-arb) también cumplen estándares internacionales, superando los prejuicios que podría tener un observador externo.
\end{abstract}

Palabras Clave: Mediación comercial, Proceso civil chino, Arbitraje internacional.

ABSTRACT: This article analyzes alternative forms of mediation available to foreign enterprises for resolving their commercial disputes in China, highlighting the defining characteristics of each form of mediation. Institutional commercial mediation is an out-of-court private mediation process conducted through a professional mediation institution. This form of mediation is consistent with the usual characteristics of modern mediation, but for various reasons it is underutilized by foreign enterprises. Despite some individual lapses, the med-arb procedure (i.e. mediation procedure within an arbitration) is generally in line with international practice. Court mediation remains the most problematic form of conciliatory dispute resolution method. Local protectionism, the policy preference for settling lawsuits and the absence of judicial independence have made court mediation structurally deficient. As long as the principle of voulntariness is upheld, mediation is a cost-effective way for resolving commercial disputes in China.

Key words: Commercial Mediation, Chinese Civil Procedure, International Arbitration.

\footnotetext{
Profesor de la Escuela de Derecho (teaching fellow), Universidad de la Ciudad de Hong Kong - Abogado en Hong Kong, Inglaterra y Gales (pchchan@cityu.edu.hk).

Una versión anterior de este artículo fue publicada en inglés en: CHAN, P.C.H., 'Mediation options for resolving commercial disputes in China: A guide for foreign enterprises', Tijdschrift voor Civiele Rechtspleging, 2012, No 2, p. 49-56. Este artículo ofrece una actualziación tanto en el Derecho sustantivo como en el procedimiento (incorporando los cambios acaecidos desde la revision del Código Procesal Civil de la República Popular China hecha en el 2012) desde la publicación anterior. El autor desea expresar su sincera gratitud a Pablo BravoHurtado -investigador de PhD, Maastricht University, Holanda (pablo.bravohurtado@maastrichtuniversity. nl)- por traducir este artículo al español.
} 


\section{INTRODUCCIÓN}

China se ha convertido en el mayor socio comercial para Chile en un lapso de diez años. Actualmente, el 22,3\% de las exportaciones chilenas están dirigidas a ese destino. En segundo lugar se encuentra la Unión Europea $(15,6 \%)$ y tercero Estados Unidos $(11,9 \%)^{1}$. Esto se debe, por una parte, al tamaño y crecimiento de la economía china y, por la otra, a que el Estado chileno celebró un tratado de libre comercio con China que comenzó a regir en octubre del $2006^{2}$.

Sin embargo, el incremento en las relaciones comerciales requiere ir a la par de una mayor comprensión del sistema jurídico chino. La Revista Chilena de Derecho comenzó el entendimiento mutuo el 2009, publicando el trabajo Zhang sobre la evolución de la codificación civil en China ${ }^{3}$. El artículo que ahora ofrezco puede ser visto como la continuación de ese entendimiento. Mientras el trabajo de Zhang aportó una aproximación al Derecho sustantivo que regula las relaciones privadas en China; este artículo aportará una aproximación al Derecho procesal disponible para resolver las disputas que se den en esas relaciones privadas, especialmente cuando está involucrada una parte extranjera. Dadas las dificultades con el sistema judicial chino, como veremos, nuestro foco de atención debe estar dirigido hacia las opciones de mediación.

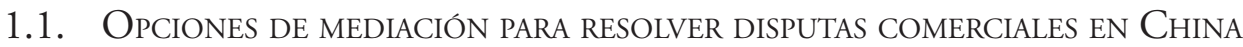

En general, hay tres opciones de mediación para resolver disputas comerciales en China: mediación judicial, mediación dirigida en el curso de un procedimiento arbitral (comúnmente llamado "med-arb") y la mediación privada a través de terceras instituciones profesionales de mediación (también conocidas como mediación comercial institucional). La mediación comercial institucional está altamente profesionalizada. Se han establecido reglamentos y códigos de conducta para los mediadores. Los mediadores son bien entrenados y están equipados con experiencias y conocimientos relevantes. Los principios fundamentales de la mediación comercial moderna (como el beneficio de la ausencia de prejuicio y la imparcialidad del mediador) están consagrados en las reglas de mediación y del procedimiento. Aparte de ciertos lapsos individuales, los procesos de med-arb realizados por la Cámara China de Arbitraje Económico Internacional y Comercial (en adelante por su sigla en inglés "CIETAC" - China International Economic and Trade Arbitration Commission) y las principales cámaras locales de arbitraje están generalmente en línea con las prácticas internacionales. El área con problemas es la conciliación judicial (que es un tipo de mediación judicial). Hay preocupaciones respecto de la imparcialidad del juez que conduce la audiencia, que actúa tanto como el adjudicador y el conciliador. La confidencialidad de la información revelada sin prejuicios durante la etapa de conciliación también está en riesgo si la conciliación falla y la audiencia continúa bajo el mismo juez.

\footnotetext{
${ }^{1}$ Dirección General de Relaciones Económicas Internacionales (2012) pp. 25-27.

${ }^{2}$ Texto disponible on-line en: http://www.direcon.gob.cl/sites/default/files/bibliotecas/CH_TN_0906_texto_completo.pdf.

3 ZHANG (2009) pp. 467-503.
} 


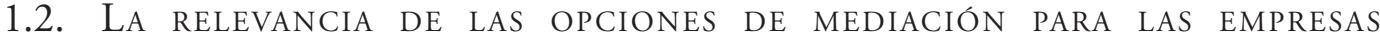 EXTRANJERAS}

La mediación comercial institucional provee a las empresas extranjeras una vía efectiva, en relación a los costos que involucra, para resolver disputas comerciales sin tener que recurrir a la litigación o al arbtraje $e^{4}$. Los mediadores son altamente profesionales y con vasta experiencia. Una transacción acordada durante una mediación puede ser transformada en un laudo arbitral que puede ser directamente ejecutado en los tribunales chinos. La mayoría de los casos que se llevan ante mediación comercial institucinal llegan a acuerdo. A la fecha, la mediación comercial institucional está subutilizada por las empresas extranjeras. Esto se debe, en parte, al error común de creer que a la mediación china (dada su tradición de resolución de disputas) no respeta la imparcialidad o la autonomía de las partes 5 . La realidad es precisamente lo contrario. La mediación comercial institucional es, en general, confiable y en línea con los principios de la mediación moderna. Los esfuerzos deben ir en la dirección de corregir ese error común y promover la mediación comercial institucional como una ADR viable para las empresas extranjeras.

La mediación judicial es una parte integral del procedimiento civil chino contemporáneo. La mediación judicial es casi inevitable si la empresa extranjera litiga en un tribunal chino, dadas las políticas actuales que la promueven. En el Anuncio de la Corte Suprema Popular sobre la implementación del principio de "dar prioridad a la mediación y combinar mediación con sentencia" (en adelante "CSP Anuncio 2010") ${ }^{6}$, la Corte Suprema Popular hizo oficial su posición que la mediación judicial es el método preferente para resolver disputas civiles y comerciales. Mientras el consentimiento está establecido en la ley como un prerrequisito para la mediación (ej. el principio de libre albedrío de las partes) ${ }^{7}$, hay una discrepancia notable entre la ley y la práctica ${ }^{8}$. A veces las partes terminan siendo persuadidas, inducidas o presionadas por el juez a mediar. Una empresa extranjera puede verse involucrada en una mediación judicial incluso si no tenía la intención de mediar desde un comienzo. La razón que subyace a esta preferencia del juez a favor de la mediación judicial es el modo en que el desempeño del juez es evaluado. El trabajo del juez se evalúa en atención a su habilidad para evitar errores y minimizar la revocación de sus sentencias cuando son apeladas. La adjudicación (que involucra tomar una sentencia) es "riesgoso" para un juez dada la posibilidad de que esta sea revocada en la apelación o que sea acusado de aplicar incorrectamente el Derecho. La mediación se vuelve para él una alternativa atractiva. Mientras la ley

\footnotetext{
4 Véase: http://adr.ccpit.org/typeinfo.aspx?t1=15\&t2=39.

5 Peerenboom y Scanlon (2005) p. 41.

${ }^{6}$ CSP (vigente desde el 7 de junio de 2010) No 16.

7 Ley del Proceso Civil Artículo 93. Nótese que la Ley del Proceso Civil (que entró en vigor en 1991) ha sido reformada dos veces, en el 2007 y 2013 respectivamente. La segunda modificación fue aprobada el 31 de agosto del 2012 (por medio de la Decisión del Comité Permanente del Congreso Popular Nacional sobre Reformas a la Ley del Proceso Civil de la Republica Popular China (2012)) y entró en vigencia el 1 de enero del 2013. Las referencias en este artículo son a la última versión de la Ley del Proceso Civil, la del 2013.

8 Clarke (1996) p. 81.
} 
enfatiza la autonomía de las partes, el tribunal usualmente domina el proceso de mediación y conduce la negociación del acuerdo a lo largo de su agenda de juicios?

La mediación realizada durante un procedimiento de arbitraje (en adelante "med-arb") es un componente integral del arbitraje en CIETAC y del que se realiza en las cámaras locales de arbitraje, como en la Cámara de Arbitraje de Beijing (en adelante "BAC"). Kaufmann-Kohler y Fan han observado que "la objeción que surgió en algún lugar contra esa visión combinada [med-arb], ahora es menos fuerte y los opositores están empezando a ver que tal combinación puede tener sus virtudes" ${ }^{10}$. El arbitraje se ha vuelto cada vez más utilizado entre las empresas extranjeras. Debido a las preocupaciones con los tribunales chinos (por ejemplo, la falta de imparcialidad del tribunal que resulta del proteccionismo local), las empresas extranjeras encuentran en el arbitraje una alternativa atractiva por sobre la litigación. En línea con las políticas que promueven la mediación en China, las cámaras arbitrales suelen promover el proceso de med-arb, incluso con sus potenciales trampas. A pesar de ciertos lapsos individuales, med-arb en China generalmente es acorde con las prácticas internacionales. CIETAC y las cámaras arbitrales locales más importantes (particularmente la BAC) han sido activos en tomar medidas para afianzar el debido proceso dentro del med-arb ${ }^{11}$.

\section{BREVE DESCRIPCIÓN DEL SISTEMA DE RESOLUCIÓN DE DISPUTAS EN CHINA}

Las empresas extranjeras involucradas en mediaciones comerciales en China están interesadas en entender el contexto básico del sistema de resolución de disputas del país. A continuación se hará una descripción breve del sistema chino de tribunales y del régimen de arbitraje.

\subsection{El SISTEMA CHINO DE TRIBUNALES}

En China no hay tribunales comerciales propiamente tales. Toda la litigación comercial se rige por la Ley de Procedimiento Civil de la República Popular China (reformada el 2012, en adelante "Ley Procesal Civil") ${ }^{12}$. Las disputas comerciales que involucran a partes extranjeras son competencia de la Cuarta Sala Civil del tribunal ${ }^{13}$. Las empresas extranjeras pueden iniciar procedimientos a cualquier nivel de los tribunales, aunque generalmente se recomienda comenzar por los tribunales superiores ${ }^{14}$. El sistema chino de tribunales tiene cuatro niveles: el nivel básico del tribunal popular en las comunas, el tribunal popular intermedio en las ciudades o en prefecturas, el alto tribunal popular a nivel de las provincias,

\footnotetext{
9 Fu y Cullen (2011) p. 51.

10 Kaufmann-Kohler y Fan (2008) p. 492.

11 Véase, por ejemplo, el artículo 58(2) de las Reglas de Beijing sobre la Cámara de Arbitraje.

12 Vigente desde el 9 de abril del 1991; reformado el 28 de octubre del 2007 y el 31 de agosto del 2012.

13 CHEN (2011) p. 180-183.

14 ZHANG (2002) p. 59-96 at p. 61-64. También véase Ley del Proceso Civil del 2013, artículos 18, 19 y 20; ver asimismo Notice on Taking of Cases Concerning Civil and Commercial Disputes at Higher Court of Provinces for the Trial of First Instance dictada por la CSP (1999).
} 
y la Corte Suprema Popular (en adelante "CSP”) en la cúspide del sistema judicial ${ }^{15}$. La CSP supervisa el trabajo de los tribunales inferiores. También cumple un rol regulatorio respecto de las opiniones judiciales, y las interpretaciones de la CSP (en materias relacionadas con justicia y procedimientos civiles) son de facto "instrumentos legislativos". La Ley del Proceso Civil debe ser leído en conjunto con estas opiniones e interpretaciones.

Bajo el sistema chino de apelaciones, la sentencia de segunda instancia marca la preclusión final del proceso civil (liangshen zhongshen zhi) ${ }^{16}$. Los críticos cuestionan si esta etapa es realmente final y conclusiva dado que es fácil reabrir los procedimientos de segunda instancia ${ }^{17}$. La falta de una verdadera preclusión de las sentencias civiles se mantendrá como una de las mayores incertidumbres para las empresas extranjeras que litigan en los tribunales chinos.

Hay ciertos aspectos del sistema chino de tribunales que pueden parecer peculiares desde la perspectiva de las empresas extranjeras. Un ejemplo notable es la existencia de un 'comité adjudicativo' en cada tribunal en China. Chen señaló que "en ciertos casos importantes y difíciles presentados al tribunal colegiado, antes que se dicte la sentencia, el caso primero debe ser discutido por el comité adjudicativo, y al dictar su sentencia el tribunal colegiado debe implementar la decisión del comité"18. Otro ejemplo es el sistema de consulta a los tribunales superiores (qingshi). Como Minzner notó, "los sistemas de responsabilidad judicial que sanciona a los jueces por un simple error legal también crea una serie de incentivos perversos sobre los jueces chinos. Para evitar ser revocados en la apelación, los tribunales y jueces inferiores chinos descanzan en un sistema enfermizo de consultas (qinshi) para preguntar las visiones de los tribunales y jueces superiores sobre cómo decidir casos pendientes"19.

El proteccionismo local sigue siendo una preocupación importante para las empresas extranjeras que litigan en China. Este problema es particularmente agudo en la etapa de ejecución. Al gobierno le está permitido intervenir a favor de la parte china involucrada en el juicio (ej. negocios locales o empresas estatales importantes) si un interés local o nacional está involucrado ${ }^{20}$.

No hay una verdadera independencia judicial en China. El concepto de separación de poderes está rechazado expresamente como incompatible con la realidad política de China. A lo largo de la historia imperial de país, los magistrados de las Cortes han sido siempre parte de la burocracia gubernamental en vez de un órgano judicial separado y autónomo. Esta tradición ha sobrevivido hasta hoy en día. Los Tribunales Populares son responsables frente al Congreso Popular al mismo nivel. El gobierno local sigue controlando (en principio) el presupuesto de los tribunales ${ }^{21}$. Esta vinculación fiscal entre la administración local y los tribunales refuerza el proteccionismo local.

15 Chen (2011) p. 182.

16 Liu (1999) p. 35.

17 Liu (1999) p. 36. Véase también ZHONG y Yu (2004) p. 422.

18 Chen (2011) p. 186. Véase también Peerenboom (2003) p. 81.

19 Minzner (2009) p. 58-59.

20 ZHANG (2002) p. 91.

21 Zhong y Yu (2004) p. 432; en contra véase Chen (2011) p. 209. 


\subsection{Entendiendo el régimen de arbitraje en China - limitaciones y} REFORMAS RECIENTES

El sistema chino de arbitraje está constituido por CIETAC, la Cámara China de Arbitraje Marítimo y de aproximadamente 200 cámaras locales de arbitraje establecidas a lo lagro de la nación. CIETAC sigue siendo la cámara de arbitraje más importante para las empresas extranjeras, sin perjuicio que las cámaras locales ahora pueden tomar casos que involucran elementos extranjeros ${ }^{22}$. Peernboom y He han observado que "el arbitraje CIETAC generalmente es considerado sustancialmente justo". Ellos se refieren a la encuesta realizada por la American Chamber of Commerce que mostró que hasta el "75\% de los encuestados que han tenido alguna experiencia con el arbitraje en CIETAC lo consideran tan beneficioso como otros grandes centros internacionales"23.

Las reformas recientes han fortalecido la autonomía de las partes en el arbitraje. Estos esfuerzos de cambio ayudan a promover el arbitraje en CIETAC como una vía atractiva para las empresas extranjeran en la resolución de disputas. Bajo las nuevas Reglas de Arbitraje en CIETAC (2012) (en adelante "Reglas CIETAC") ${ }^{24}$, a las partes se les permite nombrar personas fuera del panel de árbitros que pertenecen a CIETAC. Las partes pueden recomendar de uno a cinco árbitros como candidatos para presidir el arbitraje y deben presentar una lista de candidatos recomendados al CIETAC. Cuando hay solo un candidato común en la lista, él será el árbitro presidente conjuntamente nombrado por las partes. Todos los nombramientos de árbitro, sin embargo, deben ser confirmados por el Presidente del CIETAC ${ }^{25}$. Como el panel de árbitros que pertenecen a CIETAC está compuesto principalmente por árbitros de nacionalidad china, las reglas reformadas han facilitado árbitros extranjeros para las empresas extranjeras ${ }^{26}$.

A pesar de los esfuerzos reales por mejorar las reglas y el procedimiento de arbitraje, persisten ciertas debilidades. Bajo la Ley de Arbitraje de la República de China (en adelante "Ley de Arbitraje"), el arbitraje ad hoc está prohibido en China, y el arbitraje se debe realizar bajo las reglas de una cámara de arbitraje constituida conforme a Derecho ${ }^{27}$. Esto dista de ser satisfactorio dado que, como señaló Gu, "casi todos los países permiten arbitraje ad hoc en su legislación arbitral nacional" 28 .

El arbitraje es visto como una alternativa mejor a la litigación porque las empresas extranjeras generalmente desconfían de los tribunales chinos. Sin embargo, sería un error sostener que las empresas extranjeras pueden esquivar el sistema judicial tan solo recurriendo al arbitraje. Las empresas extranjeras requerirán acudir a un tribunal chino para ejecutar un laudo arbitral si la otra parte lo incumple, teniendo bienes en China. El mismo problema de proteccionismo local y corrupción dentro de la judicatura probablemente perjudi-

\footnotetext{
22 Peerenboom y He (2009) p. 28.

23 Peerenboom and He (2009) p. 29.

24 Revisado y adoptado por el CIETAC el 3 de febrero del 2012. Vigente desde el 1 de mayo del 2012.

25 Gu (2011) p. 273. Véase también Reglas CIETAC artículo 24(2) y el artículo 25(3).

26 Gu (2011) p. 273. Véase también Reglas CIETAC artículo 24(2) y el artículo 25(3).

27 Ley de Arbitraje en vigor desde 1995 y reformada el 2009, artículos 11 y 16.

28 Gu IN YU (2011) p. 276.
} 
carán a la empresa extranjera en la etapa de ejecución ${ }^{29}$. El tema de los costos también es frecuentemente pasado por alto por aquellas empresas extranjeras que prefieren el arbitraje. El arbitraje en CIETAC es más costoso, a veces sustancialmente más caro, en comparación a la litigación en los tribunales.

El principal problema con el arbitraje en China sigue siendo la ejecución de los laudos arbitrales. La ley establece un régimen de ejecución diferente para los laudos domésticos y otro para los laudos que involucran elementos extranjeros ${ }^{30}$, el régimen que se aplica a los laudos sobre asuntos extranjeros sería más favorable.

Recientemente, para un tribunal comenzó a ser bastante más difícil rechazar la ejecución de un laudo con elementos extranjeros. Cualquier rechazo de ejecutar debe basarse solo en consideraciones procedimentales estrictas (ej. que la formación del tribunal o el procedimiento arbitral incumple las reglas de arbitraje) ${ }^{31}$. En el pasado, bajo la Ley del Proceso civil (la versión reformada el 2007), el tribunal puede rechazar la ejecución de un laudo doméstico en base a un criterio tanto procesal como sustantivo. Por ejemplo, si la prueba principal es insuficiente, o un error del tribunal en la aplicación del Derecho pueden ser consideraciones admisibles para rechazar la ejecución ${ }^{32}$. Este trato preferencial ha sido fuertemente criticado por su ser inequitativo y porque tiene la consecuencia de desincentivar el arbitraje doméstico. Teniendo en consideración esas críticas, las reformas del 2012 a la Ley de Proceso Civil ya no permiten al tribunal rechazar la ejecución de un laudo doméstico en base a criterios substantivos ${ }^{33}$.

Aparte de los esfuerzos de reforma señalados más arriba, quedan otras medidas que son preferibles. Por ejemplo, los laudos sobre asuntos extranjeros pueden verse beneficiados gracias al mecanismo de consulta al tribunal superior, bajo el cual una decisión por un tribunal inferior que rechaza el reconocimiento o ejecución del laudo debe ser aprobado por la $\mathrm{CSP}^{34}$. Este sistema de consulta no es aplicable a los laudos sobre asuntos domésticos ${ }^{35}$.

Las empresas extranjeras que realizan arbitrajes dentro de China continental pueden obtener tanto un laudo-extranjero o un laudo-doméstico, dependiendo si acaso existen "elementos extranjeros" ${ }^{36}$. Si una empresa extranjera es parte en un arbitraje, el laudo obtenido será considerado laudo-extranjero (porque hay presente un elemento extranjero en

29 Gu (2011) p. 279.

30 Peerenboom (2000) p. 11

31 Ley del Proceso Civil del 2007, artículo 258.

32 Ley del Proceso Civil del 2007, artículo 213.

33 Ley del Proceso Civil del 2007, Artículo 213 ha sido modificada por la Decisión del Comité Permanente del Congreso Popular Nacinal sobre Reformas a la Ley del Proceso Civil de la República Popular China (2012). Bajo el artículo 237 de la última versión de la Ley del Proceso Civil (2013), el criterio sustantivo para rechazar la ejecución (ej. insuficiencia de la prueba principal y error en la aplicación del Derecho) ahora ha sido rechazado y reemplazado por dos criterios no substantivos (ej. cuando el laudo fue dictado sobre la base de prueba falsificada y cuando la parte ha ocultado evidencia al tribunal que pudiera afectar el debido proceso de la decisión).

34 Peerenboom (2000) p. 28-29. Véase también Notice on Courts' Handling of Issues in Relation to Matters of Foreign-related Arbitration and Foreign Arbitration issued by the Supreme People's Court in 1995.

35 Ver críticas al mecanismo de consultas en Gu (2012) p. 164.

36 Peerenboom (2003) p. 11. Véase también CSP (1991) De las Opiniones Respecto de la Implementación de Ley del Proceso Civil, artículo 304. 
virtud de la empresa extranjera que es parte en el arbitraje). Sin embargo, si una compañía de inversiones extranjera (una corporación china conducida por inversiones de una empresa extranjera, por ejemplo, un joint venture chino-extranjero) es parte en un arbitraje, es probable que el laudo obtenido sea considerado un laudo-doméstico, a menos que se pueda demostrar que existe un elemento extranjero. La razón para esto es que la compañía de inversión extranjera es considerada una persona jurídica china. Entonces, es una parte doméstica y no una parte extranjera en el arbitraje ${ }^{37}$.

\section{MEDIACIÓN COMERCIAL INSTITUCIONAL}

En China hay instituciones establecidas para resolver disputas comerciales mediante una mediación privada, cobrando una tasa administrativa. La institución más influyente es el Consejo Chino para la Promoción del Comercio Internacional / Cámara China de Comercio Internacional (en adelante "CCPCI/CCCI"), que opera como un centro de mediación con cobertura nacional (en adelante "Centro de Mediación”). Establecido en 1987, el Centro de Mediación mantiene una red nacional de más de 40 subcentros de mediación local en provincias, municipalidades y regiones autónomas. CCPCI/CCCI tiene una gran presencia en China. De acuerdo con las estadísticas oficiales, más del $80 \%$ de los casos que se sometieron a mediación en este Centro de Mediación han llegado a acuerdos ${ }^{38}$. La razón para esta alta tasa de éxito no es del todo clara. Prácticamente no hay investigaciones empíricas independientes sobre mediación comercial institucional. Norton señaló que "no hay disponible estadísiticas confiables sobre la carga de casos de estos centros de mediación" 39 . Esto posiblemente se debe a la dificultad de convencer a las partes para que revelen los resultados de la mediación a propósito de una investigación. Lejos de ser satisfactorio, la literatura existente simplemente se sostiene sobre las estadísticas oficiales publicadas por el Centro de Mediación. Asumiendo que las estadísticas oficiales son correctas, la revisión de una muestra de casos de mediación sugiere que el profesionalismo del mediador es un factor que contribuye a esta alta tasa de éxito. Los mediadores usualmente son capaces de aplicar su conocimiento experto y adoptar estrategias flexibles de mediación para acercar a las partes a un acuerdo ${ }^{40}$. Peerenboom y Scanlon observaron que la mayoría de los casos que llegaron a un acuerdo son de naturaleza doméstica y no involucraron elementos transfronterizos. Generalmente, las empresas extranjeras en China prefieren el arbitraje o la litigación para resolver sus disputas comerciales en vez de acudir a los centros de mediación privada $^{41}$. Como se señaló anteriormente, una razón de esta subutilización podría ser que las empresas extranjeras tienen temor de la mediación china (dada su tradición de resolución de disputas) carente de imparcialidad y respeto a la autonomía de las partes ${ }^{42}$. Esto es un error común toda vez que la mediación que se practica en el Centro de Mediación gene-

\footnotetext{
37 Peerenboom (2003) p. 11.

38 Véase breve resumen del Centro de Mediación disponible en: http://lad.ccpit.org/english/wadr/index.aspx.

39 Norton en Moser (eds) (2007) p. 38.

40 Disponible en http://adr.ccpit.org/typelist2.aspx? $\mathrm{t} 1=19 \& \mathrm{t} 2=56$.

41 Peerenboom y Scanlon (2005) p. 37-38.

42 Peerenboom y Scanlon (2005) p. 41.
} 
ralmente es acorde con las prácticas internacionales. El mediador está regualdo por un código profesional de conducta y las partes son libres de rechazar un acuerdo propuesto por el mediador ${ }^{43}$. Con el rápido crecimiento económico de China y la proliferación de demandas judiciales, la mediación privada por instituciones profesionales provee una forma atractiva de ADR para los negocios extranjeras.

El Centro de Mediación mantiene un panel de mediadores seleccionados entre individuos de nacionalidad china y también extranjera que posean conocimientos profesionales y experiencia práctica en comercio o en Derecho. El Centro de Mediación provee una cláusula modelo de mediación fácil de adoptar en los acuerdos comerciales ${ }^{44}$. Dado que en China no hay legislación que detalle los procedimientos para una mediación privada realizada por una institución de mediación, los acuerdos de mediación de las partes y las reglas propias de la institución de mediación son vitales para regular el desarrollo de la mediación ${ }^{45}$.

\subsection{REgLAS DE MEDIACIÓN Y CÓDIGO DE CONDUCTA - FORTALECIENDO LOS PRINCIPIOS DE LA MEDIACIÓN MODERNA}

El Centro de Mediación ha adoptado una serie de reglas uniformes sobre mediación (en adelante "Reglas de Mediación"). Todos los subconsejos de los centros de mediación tienen el deber de aplicar uniformemente estas Reglas de Mediación ${ }^{46}$. La uniformidad de reglas otorga coherencia procesal y predictibilidad para la mediación comercial privada a lo largo de China. A las partes les está permitido modificar las Reglas de Mediación (o aplicar solo algunas) en la medida en que esas modificaciones o aplicación selectivas no entren en conflicto con la ley ${ }^{47}$. Las Reglas de Mediación, en conjunto con el Código de Conducta de los Mediadores en el Centro de Mediación (en adelante "Código de Conducta"), han fortalecido los principios fundamentales de la mediación comercial moderna. Cao ha observado que -dado que el Derecho chino no reconoce el priviligio entre el mediador y las partes a la mediación ${ }^{48}$ - los principios de imparcialidad e independencia del mediador están enfatizados bajo las Reglas de Mediación y el Código de Conducta ${ }^{49}$. Además, un mediador debe mantener la confidencialidad sobre toda la información que surga dentro o fuera de la mediación (tanto de naturaleza procesal o de los hechos) ${ }^{50}$. A pesar que no hay una disposición legal en China que establezca el beneficio de la ausencia de prejuicio, las reglas

\footnotetext{
43 Peerenboom y Scanlon (2005) p. 41. Véase también Cao (2006) p. 85. Además Alexander (2009) p. 16-17.

44 Disponible en http://lad.ccpit.org/tjzx/wytjSFTK.aspx

45 CAO (2006) p. 86.

46 Centro de Mediación del Consejo Chino para la Promoción del Comercio internacional \& Cámara China de Comercio Internacional, Reglas de Mediación del 2005.

47 Reglas de Mediación del 2005, artículo 3. Véase también Ley del Proceso Civil del 2013, artículo 96. Los requisitos establecidos en el artículo 96 no pueden ser excluidos contractualmente.

48 CAO (2006) p. 87.

49 Véase Código de Conducta del 2005, artículos 2, 7, 9 y 10. Véase también Reglas de Mediación del 2005, artículos 21, 29 y 32.

50 Código de Conducta del 2005, artículo 8.
} 
establecen que las bases de acuerdo o las ofertas reveladas en la mediación no pueden ser invocadas en procedimientos posteriores ${ }^{51}$.

\subsection{Metodología y procedimiento de mediación}

El Centro de Mediación acepta casos basados sobre acuerdos de mediación acordados entre las partes tanto antes o después del acaecimiento de la disputa. Cuando no hay un acuerdo de mediación, el Centro de Mediación todavía puede aceptar el caso a partir de la solicitud hecha por una parte con el consenso de la otra parte ${ }^{52}$. El artículo 13 de las Reglas de Mediación detalla los requisitos procesales de esta solicitud. El requerido tiene quince días desde la fecha que recibe esta Solicitud de Mediación para pronunciarse si acaso está de acuerdo o no con mediar. Si el requerido no se pronuncia sobre su acuerdo para mediar dentro de este plazo, se considerará que ha rechazado la mediación ${ }^{53}$. Usualmente el solicitante y el requerido van a proponer su propio mediador, a menos que ellos acuerden nombrar uno conjuntamente ${ }^{54}$. Si cada parte propone un mediador, los dos mediadores propuestos mediarán conjuntamente la disputa ${ }^{55}$. A las partes les está permitido delegar en el Centro de Mediación el nombramiento de un mediador único para ellos ${ }^{56}$. El mediador puede adoptar los métodos de mediación que resulten más benéficas para que las partes lleguen a un acuerdo ${ }^{57}$. De acuerdo con Peerenboom y Scanlon, "los estilos de mediación varían desde los 'facilitadores' a los 'evaluadores', incluyendo diversos grados entre ambos" 58. Las Reglas de Mediación proveen una gama de métodos específicos para conducir la mediación en circunstancias particulares ${ }^{59}$.

\subsection{EJECUCIÓN DE UNA TRANSACCIÓN ACORDADA EN MEDIACIÓN}

Una transacción acordada durante una mediación es un contrato privado. A diferencia del laudo arbitral o la sentencia judicial, la transacción ahí acordada no puede ser ejecutada directamente (ej. como señaló Liang, no tiene "efecto legal o cumplimiento coactivo" ${ }^{60}$. Si una parte incumple la transacción mediada, la otra parte que busca ejecutar el acuerdo necesitará, en primer lugar, conseguir una sentencia de un tribunal (por medio de una demanda de responsabilidad contractual) y solo después ejecutar la sentencia. Esta situación dista mucho de ser satisfactoria dada la imprevisibilidad y los costos involucrados en la litigación.

Para evitar el retraso y los costos excesivos en la ejecución, se estableció un mecanismo efectivo para vincular el régimen de mediación en el CCPCI/CCCI con el régimen de arbi-

\footnotetext{
51 Reglas de Mediación del 2005, artículo 31. Véase también CaO (2006) p. 87.

52 Reglas de Mediación del 2005, artículo 11.

53 Reglas de Mediación del 2005, artículo 15.

54 Reglas de Mediación del 2005, artículo 17.

55 Wang (2005) p. 429.

56 Reglas de Mediación del 2005, artículo 19(c).

57 Reglas de Mediación del 2005, artículo 23.

58 Peerenboom and Scanlon (2005) p. 38.

59 Reglas de Mediación del 2005, artículo 23.

${ }^{60}$ LiAng (2008) p. 490.
} 
traje en CIETAC para permitir que la transacción acordada pueda ser transformada en un laudo arbitral, que sea ejecutable directamente. Este meanismo está consagrado tanto en las Reglas de Mediación como en las Reglas CIETAC $^{61}$. Las partes tienen la opción de insertar una cláusula arbitral en la transacción acordada durante la mediación en el Centro. Cuando una transacción es presentada, cualquiera de las partes puede postular al arbitraje en CIETAC. Este después nombra a un arbitrador único para examinar el caso solo sobre la base de documentos. Como señaló Hilmer, el árbitro único puede dictar un laudo-confirmatorio en los mismos términos de la transacción acordada y "los honorarios cobrados por el arbitraje se pueden reducir en consideración a la cantidad de trabajo involucrado y los gastos efectivos en que incurrió CIETAC”62. El laudo-confirmatorio es ejecutable como cualquier otro laudo.

En consideración de las dificultades para ejecutar una transación acordada durante una mediación, la CSP dictó las Diversas Opiniones de la Corte Suprema Popular sobre el Establecimiento de un Mecanismo de Resolución de Disputas que conecte litigación y no litigación (en adelante "CSP Opinión 2009") para acelerar el proceso ${ }^{63}$. Para una transacción alcanzada en una mediación que involucra solo un pago monetario, las partes pueden asegurar el cumplimiento a través de la notarización o mediante una solicitud al tribunal popular básico que tenga competencia sobre esa orden de pago ${ }^{64}$. Para transacciones más complejas (que involucren obligaciones distintas a un pago monetario), la Opinión 2009 de la CSP introduce un procedimiento judicial de confimarción que es rápido y estandarizado. Bajo tal procedimiento, las partes pueden solicitar conjuntamente al tribunal que tenga competencia y presentar la transacción mediada y una letra de compromiso firmada por las dos partes $^{65}$. El tribunal deberá aplicar por analogía las disposiciones relevantes de la Ley del Proceso Civil sobre el procedimiento sumario para confirmar la transacción acordada. El caso debe ser tramitado por un solo juez. Ambas partes deben comparecer ante el tribunal al mismo tiempo. El tribunal preguntará a ambas partes, cara-a-cara, si acaso entienden el contenido del acuerdo, si acaso ellas aceptan los efectos que se siguen y si permiten al tribunal garantizar su exigibilidad del acuerdo mediante el procedimiento de confirmación judicial $^{66}$. El tribunal decidirá, a partir de la revisión del caso, si acaso confirma el acuerdo. Una transacción cofirmada es ejecutable una vez que sea notificada a ambas partes ${ }^{67}$. Hay ciertos casos donde el tribunal debe rechazar la confirmación del acuerdo ${ }^{68}$.

\subsection{Centros de mediación COnjunta}

El artículo 6 de las Reglas de Mediación permite que el Centro de Mediación dirija mediaciones con otras instituciones de resolución de disputas, o acepte la invitación de otras instituciones a mediar conjunta o solitariamente. Sobre esa base, el Centro de Me-

${ }^{61}$ Reglas de Mediación del 2005, artículo 27. Véase también de las Reglas del CIETAC, artículo 45(10).

62 Hilmer (2009) p. 102-103.

63 CSP Opinión (2009) No 45 que ha estado en vigencia desde el 24 de julio del 2009.

${ }^{64}$ CSP Opinión (2009), artículos 12 y 13.

65 CSP Opinión (2009), artículo 22.

66 CSP Opinión (2009), artículo 23.

67 CSP Opinión (2009), artículo 25.

68 CSP Opinión (2009), artículo 24. 
diación ha establecido numerosos centros de mediación con contrapartes internacionales (ej. desde Alemania, Estados Unidos, Reino Unido e Italia) con el objetivo de promover la resolución de disputas relacionadas con extranjeros a través de mediación privada ${ }^{69}$. Norton ha observado que los centros de mediación conjunta han sido subutilizados en China. La razón por la cual esto sucede "no está del todo clara"70.

\subsection{MEDiACiÓN COMERCIAL NO-INSTITUCIONAL}

La mediación comercial no institucional refiere a la mediación comercial privada conducida por un tercero imparcial como mediador al margen del régimen CCPIT/ CCOIC. No ha habido un estudio comprehensivo o un repositorio de estadísticos en materia de mediación no institucional. Al igual que con la mediación institucional, las partes que han logrado una transacción voluntaria en una mediación no institucional pueden sostenerse en el artículo 45(10) de las Reglas CIETAC (sobre la base de una transacción en arbitraje) para asegurar un laudo consensual.

\section{MEDIACIÓN JUDICIAL Y SU IMPACTO EN LA RESOLUCIÓN DE DISPUTAS COMERCIALES}

Las disputas comerciales que llegan a los tribunales populares pueden llegar a acuerdo a través de una mediación judicial, que es una parte integral del procedimiento civil chino $^{71}$. Los dos principios básicos que subyacen en la mediación judicial china son: legalidad y voluntariedad (de la partes) ${ }^{72}$. La voluntariedad de las partes en la mediación judicial proviene del principio dispositivo. También promueve el cumplimiento de un acuerdo mediado $^{73}$. Lamentablemente, la voluntariedad en la mediación judicial está en riesgo como resultado de ciertos factores que serán explicados más abajo.

La mediación judicial puede ser realizada en varias etapas de un procedimiento civil (primera instancia, apelación o revisión del caso). Las reglas procesales para la mediación judicial están establecidas en las Provisiones de la Corte Suprema Popular sobre Diversos Asuntos Concernientes al Funcionamiento de la Mediación Civil de los Tribunales Populares (en vigencia desde el 1 de noviembre del 2004, en adelante "CSP Provisiones 2004”). El tribunal puede invitar a otras entidades (o individuos) que tengan una especial relación con las partes o estén conectadas con el caso para asistir en la mediación judicial $7^{74}$. Las partes, así como el equipo

\footnotetext{
${ }_{69}$ Véase también: http://www.cpradr.org/Resources/ALLCPRArtículos/tabid/265/ID/625/The-CPRCCPITMediation-Procedure-for-Disputes-Submitted-to-the-US-China-Business-Mediation-Center.aspx.

70 Norton en Moser (ed.) (2007) p. 39-40.

71 Alexander (2009) p. 139.

72 Ley del Proceso Civil del 2013, artículos 9, 93 y 96.

73 Office for Civil LaW de la Legislative Affairs Commission of the National People's Congress Standing Committee (ed.), Zhonghua renmin gongheguo minshi susongfa: tiaowen shuoming lifa liyou ji xiangguan guiding ["La Ley del Proceso Civil de la República Popular China: Explicación de las Disposiciones, Razones Legsilativas y Reglas Relevantes”] (2007) p. 155.

74 CSP Disposiciones del 2004, artículo 3. Véase también Ley del Proceso Civil del 2013, artículo 95.
} 
que preside la mediación, pueden formular una propuesta de mediación ${ }^{75}$. Cuando se logra un acuerdo a través de la mediación judicial, el tribunal deberá redactar un "acuerdo de mediación" por escrito. Un acuerdo de mediación debe establecer claramente las pretensiones de la demanda, los hechos del caso y el resultado de la mediación. El acuerdo de mediación debe después ser firmado por el juez, los asistentes del tribunal, sellado por la Corte y notificado a ambas partes. Una vez que el acuerdo de mediación está firmado y entregado a ambas partes, se vuelve jurídicamente vinculante ${ }^{76}$. Si una de las parte incumple el acuerdo de mediación, la otra puede solicitar al tribunal la ejecución del acuerdo ${ }^{77}$.

La mediación judicial generalmente incluye dos procedimientos distintos: la mediación prejudicial y la conciliación judicial. La mediación prejudicial tiene lugar en la etapa de formación del expediente. Usualmente está dirigido por el juez o por un funcionario judicial ${ }^{78}$. El juez que dirige la mediación debe ser distinto al juez de la audiencia de juicio $^{79}$. La conciliación judicial tiene lugar después de la formación del expediente hasta la audiencia de juicio. En la conciliación judicial, el juez de la audiencia de juicio actúa como conciliador. Si la conciliación fracasa, el mismo juez continuará con la adjudicación el caso. Esta práctica probablemente amenaza la ausencia de prejuicios que debería ser de la naturaleza del proceso de conciliación (particularmente dado que al juez se le permite reunirse ex parte con los litigantes) ${ }^{80}$ y la imparcialidad del juez en la adjudicación que le seguirá. La conciliación judicial puede ocurrir en la fase de cierre de la audiencia de juicio, justo antes de que se dicte la sentencia mientras las partes consientan la mediación ${ }^{81}$.

Después de una caída en las tasas de acuerdo en la mediación judicial en la década de 1990, la mediación judicial ha resurgido como la herramienta preferida para la resolución de disputas desde el 2002. Hay fuertes razones políticas tras de esto ${ }^{82}$. El énfasis de la judicatura sobre la mediación judicial tiene razones presupuestarias y de administración del caso. Peerenboom y He observaron que la CSP y el Ministro de Justicia estaban preocupados porque la proliferación de las apelaciones civiles puedan sobrecargar a las Cortes y agregan un costo inconmensurable al sistema judicial chino ${ }^{83}$. Otra razón para la preferencia judicial por la mediación, como señalaron Peerenbom y Scanlon, es que los jueces "son evaluados, en parte, a partir de cuántas de sus sentencias son revocadas en apelación" ${ }^{44}$. A diferencia de llegar a una sentencia, los acuerdos de mediación no están sujetos a apelación (aunque las partes tienen una oportunidad estrecha de impugnar el acuerdo esgrimiendo que hubo coacción o violación del Derecho) ni tampoco están sujetos a peticiones administrativas (shang fang). El resultado de esta política y de la tendencia judicial a favor de la me-

\footnotetext{
75 CSP Disposiciones 2004, artículo 8.

76 Ley del Proceso Civil del 2013, artículo 97.

77 CSP Disposiciones del 2004, artículo 13.

78 Véase también CSP Opinión 2009, artículo 15.

79 CSP Opinión (2009) artículo 16.

${ }^{80}$ CSP Disposiciones del 2004, artículo 7.

81 CSP Disposiciones del 2004, artículo 1.

82 CSP Noticia (2010) artículo 1.

83 Peerenboom y He (2009) p. 26.

84 Peerenboom and Scanlon (2005) p. 40.
} 
diación judicial, las partes en una disputa comercial pueden ser forzadas a mediar su caso y volverse "víctimas" de un acuerdo forzado ${ }^{85}$. Cuando una parte se ve involucrada en una transacción contra su voluntad, es más probable que no la cumpla. Eso lleva a problemas en la ejecución.

Sería una falacia concluir que en China la mediación judicial de las disputas comerciales ha sido exitosa simplemente observando las tasas de transacciones acordadas. Si las transacciones mediadas frecuentemente están sujetas a ejecución judicial, la conclusión necesariamente debería ser que la mediación no ha sido efectiva en primer lugar ${ }^{86}$. La ejecución de una transacción acordada por una mediación judicial se ha vuelto cada vez más problemática ${ }^{87}$. Mientras la tasa de acuerdos en la mediación judicial ha aumentado, entre el periodo del 2002 al 2009, la tasa de ejecución judicial se disparó en el mismo periodo $^{88}$. Esto sugiere que un número considerable de transacciones mediadas no resolvieron la disputa y las partes han acudido a los tribunales para obtener ejecución. Esta situación es particularmente seria en los tribunales populares a nivel básico ${ }^{89}$.

La mediación judicial también tiene sus virtudes ${ }^{90}$. Puede acelerar la resolución de disputas comerciales y ahorrar costos. Asimismo, otorga una resolución final de la disputa, toda vez que el acuerdo no puede ser apelado. Pero, como advirtió Wang, la mediación judicial no se debe enfatizar demasiado ${ }^{91}$, porque resultaría en un deterioro de la función adjudicadora del tribunal (especialmente en la averiguación de los hechos) dado que el foco habrá cambiado desde el cumplimiento de los derechos hacia la mera resolución de disputas ${ }^{92}$.

\section{MED-ARB: MEDIACIÓN DENTRO DEL ARBITRAJE CIETAC}

Cuándo a un tribunal arbitral le debería estar permitido mediar durante el curso de un arbitraje, es algo que ha despertado un debate internacional ${ }^{93}$. Tanto las Reglas CIETAC como la Ley de Arbitraje permiten al tribunal arbitral también actuar como un mediador durante el arbitraje ${ }^{94}$. Este procedimiento de mediación es conocido como "med-arb". Med-arb puede darse tanto cuando ambas partes conjuntamente buscan mediar como también si una de ellas lo busca y la otra lo acepta cuando se lo plantea el tribunal arbitral. El tribunal arbitral puede mediar un caso de la manera que considere adecuado. El tribunal debe terminar la mediación y continuar el procedimiento arbitral si una de las partes exige el término de la mediación o si el tribunal arbitral cree que serán inútiles mayores esfuerzos

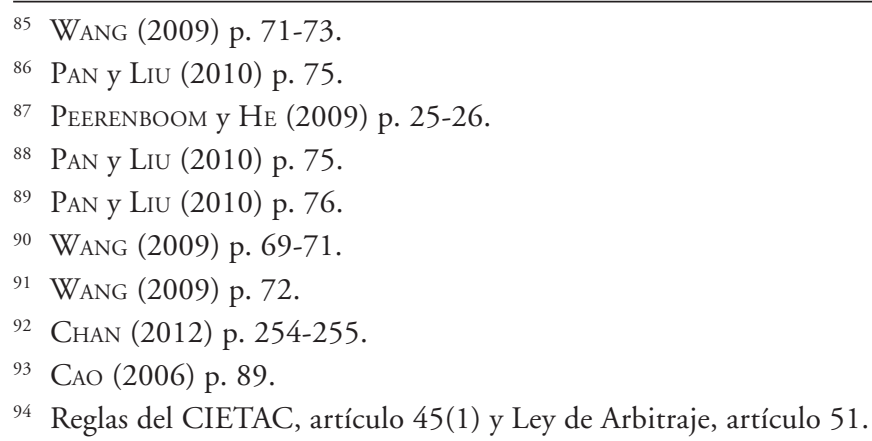


por mediar ${ }^{95}$. Cuando la mediación falla, toda opinión, afirmación o cualquier propuesta que exprese la aceptación o rechazo de las partes o del tribunal en el proceso de mediación no debe ser invocado como fundamento de la demanda, contestación o reconvención en los procedimientos de arbitraje o litigación judicial que le $\operatorname{sigan}^{96}$. Cao ha observado que la mediación típicamente "toma lugar después de los alegatos de las partes y el examen de la prueba en la audiencia oral”. El tribunal procederá a la mediación con el consentimiento de las partes "cuando perciba que hay una posibilidad de acuerdo" ". Cao señaló después que las técnicas de mediación utilizadas en el med-arb incluyen la aproximación "cara-acara" (donde la mediación es realizada en presencia de todas las partes) y la aproximación "espalda-con-espalda" (donde el mediador interactúa con cada parte separadamente) ${ }^{98}$. Si el acuerdo se alcanza a través de la mediación en el tribunal arbitral, las partes deberán firmar el escrito de transacción acordada. La transacción alcanzada por las propias partes durante el curso del med-arb sin el involucramiento del tribunal arbitral es considerada como un acuerdo alcanzado a través de la mediación por el tribunal ${ }^{99}$.

De acuerdo con Wang, "tres principios fundamentales" subyacen al med-arb en los procedimientos arbitrales del CIETAC. Primero, la mediación es "una opción para las partes y no requiere necesariamente de un procedimiento de arbitraje" ${ }^{100}$. Segundo, la autonomía de las partes debe ser respetada. En un nivel sustantivo, cualquier acuerdo debe ser alcanzado sobre la base "de la absoluta voluntad libre de las partes". A un nivel procesal, señaló Cao, las partes tienen el poder abosulto para determinar cuándo iniciar o terminar el proceso de mediación ${ }^{101}$. Tercero, siguiendo un principio central en la mediación judicial $^{102}$, el med-arb de CIETAC debe ser conducido con el objetivo de distinguir lo correcto y lo incorrecto basado en hechos claros ${ }^{103}$.

Mientras prevalezca el principio de autonomía de las partes, al tribunal se le otorgan facultades para facilitar la conciliación (incluso el poder de proponer los términos del acuerdo). El tribunal arbitral debe ser muy cuidadoso al ejercer estas facultadas y evitar que surga algún sesgo. Por ejemplo, si hay un riesgo que se favorezca a una parte sobre la otra al presentar una propuesta de acuerdo, el tribunal probablemente anulará el laudo sobre la base de que el procedimiento de arbitraje adolecería de un prejuzgamiento ${ }^{104}$. En la práctica, Peerboom y Scanlon observaron que "los árbitros pueden estar inclinados a presionar en la mediación para evitar tener que decidir cuando los hechos o el Derecho no están claros, para ahorrar tiempo y esfuerzos, [o] para reducir los potenciales problemas en la fase de ejecución". Ellos notaron además que algunas partes extranjeras han reportado "sentirse

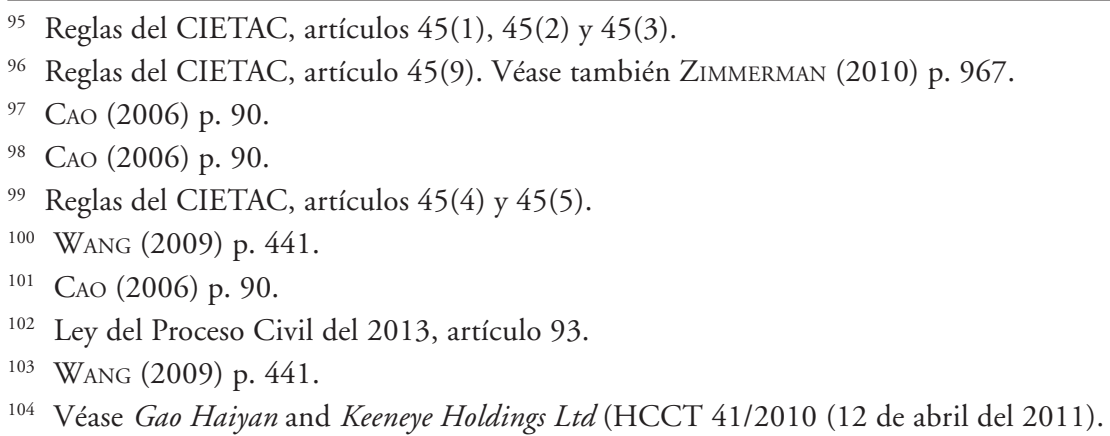


presionadas para mediar y aceptar el acuerdo"105. Las empresas extranjeras también están preocupadas porque los árbitros puedan hacer mal uso de la información confidencial obtenida durante el med-arb, información que de otra forma no habrían obtenido durante el curso de una audiencia arbitral normal ${ }^{106}$.

\section{CONCLUSIÓN}

Además de ahorrar costos, tiempo y relaciones comerciales, la mediación tiene una ventaja única en China. En este país la ejecución de laudos arbitrales y sentencias judiciales son particularmente difíciles. Las partes están más dispuestas a cumplir una transacción voluntaria (acordada a través de una mediación) por sobre un laudo o una sentencia ${ }^{107}$. Sin embargo, esta ventaja solo puede ser disfrutada si el proceso de mediación está basado en las deliberaciones voluntarias de las partes, libre de interferencias externas. La mediación comercial institucional cumple con estándares internacionales. Los mediadores actúan profesional e imparcialmente. Les permite a las partes la flexibilidad de elegir los procedimientos para mediación. El med-arb conducido por el CIETAC y por las cámaras locales de arbitraje están generalmente en línea con las prácticas internacionales. La mediación judicial sigue siendo problemática, toda vez que la voluntariedad de las partes está coartada dentro de una cultura de acuerdos institucionalizados. Reformar la mediación judicial en China es absolutamente necesario.

\section{BIBLIOGRAFÍA}

Alexander, N. (2009): International and Comparative Mediation: Legal Perspectives (Alphen aan den Rijn, Kluwer Law International).

CaO, L.J. (2006): "Combining Conciliation and Arbitration In China: Overview and Latest Developments", International Arbitration Law Review, Vol. 9 no 3: pp. 84-93.

Chan, P.C.H. (2012): Efficiency and Truth in Civil Fact-finding: The Evolving Role of the Judge in Mainland China and Hong Kong and the Effect of the Policy Preference for Court Mediation on Fact-finding in the People's Courts, in: Van Rhee, C.H. y Uzelac, A. (edits.), Truth and Efficiency in Civil Litigation: Fundamental Aspects of Fact-finding and Evidence-taking in a Comparative Context (Antwerp: Intersentia) pp. 231-260.

Chen, A.H.Y. (2011): An Introduction to the Legal System of the People's Republic of China (Hong Kong, Editorial LexisNexis, cuarta edición).

Clarke, D.C. (1996): "Power and Politics in the Chinese Court System: The Enforcement of Civil Judgments", Columbia Journal of Asian Law, n 10: pp. 1-92.

Fu, H.L. y Cullen R. (2011): From Mediatory to Adjudicatory Justice: The Limits of Civil Justice Reform in China en Woo, M.Y.K. and Gallagher, M.E. (edits.), Chinese Justice:

\footnotetext{
105 Peerenboom and Scanlon (2005) p. 40.

106 Peerenboom y Scanlon (2005) p. 40.

107 Peerenboom y Scanlon (2005) p. 41.
} 
Civil Dispute Resolution in Contemporary China (New York, Cambridge University Press): pp. 25-57.

Gu, W.X. (2011): China's Arbitration: Restricted reform, in Yu, G.H. (ed.), The Development of the Chinese Legal System (Oxford: Routledge): pp. 272-292.

Gu, W.X. (2012): Arbitration in China: Regulations of Arbitration Agreements and Practical Issues (Hong Kong, Sweet \& Maxwell).

Hilmer, S. E. (2009): Mediation in the People's Republic of China and Hong Kong (SAR) (Utrecht, Eleven International Publishing).

Kaufmann-Kohler, G. and Fan, K. (2008): "Integrating Mediation into Arbitration: Why It Works in China”, Journal of International Arbitration, vol. 25 n4: pp. 479-492.

Liang, J.Q. (2008): "The Enforcement of Mediation Settlement Agreements in China", American Review of International Arbitration, $\mathrm{n}^{\circ}$ 19: pp. 489-519.

Liu, N.P. (1999): "A Vulnerable Justice: Finality of Civil Judgments in China”, Columbia Journal of Asian Law, ${ }^{\circ}$ 13: pp. 35-98.

Minzner, Carl (2009): “Judicial Disciplinary Systems for Incorrectly Decided Cases: The Imperial Chinese Heritage Lives On” en Woo, M.Y.K. and Gallagher, M.E. (edits.), Chinese Justice: Civil Dispute Resolution in Contemporary China (New York, Cambridge University Press): pp. 58-90.

Norton, P.M. (2007): Informal Dispute Settlement Approaches in Moser, M. J. (eds.), Managing Business Disputes in Today's China: Duelling with Dragons (Alphen aan den Rijn, Kluwer Law International): pp. 19-44.

Pan, J.F. y LiU, Z.W. (2010): "Lun fayuan tiaojie yu jiufen jiejue zhi guanxi - cong goujian hexie shehui de jiaodu zhankai” [La Relación entre la Mediación Judicial y la Resolución de Disputas - Desde la Perspectiva de la Construcción de una Sociedad Armonioza], Journal of Comparative Law, $\mathrm{n}^{\circ}$ 4: pp. 70-81.

Peerenboom, Randall (2003): “The X-Files: Past and Present Portrayals of China's Alien 'Legal System'”, Washington University Global Studies Law Review, vol. 2: pp. 37-95.

Peerenboom, R. y Scanlon, K. (2005): "An Untapped Dispute Resolution Option: Mediation Offers Companies Distinct Advantages in Certain Cases", The China Business Review, vol. 32 n4: pp. 36-41.

Peerenboom, R. y He, X. (2009): "Dispute Resolution In China: Patterns, Causes and Prognosis”, East Asia Law Review, n 4: pp. 1-61.

Wang, L.M. (2009): “Characteristics of China’s Judicial Mediation System”, Asia Pacific Law Review, vol. 17 n 2: Supp. (Special Issue on Mediation) pp. 67-74.

Wang, W.Y. (2005): "The Role of Conciliation in Resolving Disputes: A P.R.C. Perspective", Ohio State Journal on Dispute Resolution, vol. 20: p. 421-449.

Zhang, M. (2002): "International Civil Litigation in China: A Practical Analysis of the Chinese Judicial System", Boston College International and Comparative Law Review, ${ }^{\circ}$ 25: pp. 59-96.

ZHANG, L., (2009): "Los últimos avances en la codificación del Derecho Civil chino", Revista Chilena de Derecho, vol. 36 no 3: pp. 467-503. 
Zhong, J.H. y YU, G.H. (2004): "Establishing the Truth on Facts: Has the Chinese Civil Process Achieved This Goal?” Journal of Transnational Law \& Policy, vol. o n¹3: pp. 393-445.

Zimmerman, J. M. (2010): China Law Deskbook: A Legal Guide for Foreign-Invested Enterprises (Chicago, American Bar Association, tercera edición).

\section{DOCUMENTOS OFICIALES}

Dirección General de Relaciones Económicas Internacionales (2012), Informe comercio exterior 3er semester 2012 (Ministerio de Relaciones Exteriores de Chile, 2012), pp. $25-27$.

Centro de Mediación del Consejo Chino para la Promoción del Comercio Internacional \& Cámara China de Comercio Internacional (2005): Reglas de Mediación (Vigente desde julio de 2005).

Corte Suprema Popular (1995) Notice on Courts' Handling of Issues in Relation to Matters of Foreign-related Arbitration and Foreign Arbitration.

Corte Suprema Popular (1999) Notice on Taking of Cases Concerning Civil and Commercial Disputes at Higher Court of Provinces for the Trial of First Instance.

Corte Suprema Popular (2009) Opinión No 45, en vigencia desde el 24 de julio de 2009.

Corte Suprema Popular (1991): Opiniones Respecto de la Implementación de Ley del Proceso Civil.

Office for Civil Law de la Legislative Affairs Commission of the National People's Congress Standing Committee (2007): Zhonghua renmin gongheguo minshi susongfa: tiaowen shuoming lifa liyou ji xiangguan guiding (ed.) [La Ley del Proceso Civil de la República Popular China: Explicación de las Disposiciones, Razones Legislativas y Reglas Relevantes] (Beijing: Peking University Press).

\section{NORMAS CITADAS}

Ley del Proceso Civil de 2007 (última modificación publicada el 1 de enero de 2013): Art. 9, Art. 93, Art. 95, Art. 96, Art. 97, Art. 213, Art. 237, Art. 258, Art. 304.

Reglas de Mediación de 2005: Art. 11, Art. 15, Art. 17, Art. 19(c), Art. 21, Art. 23, Art. 29, Art. 27, Art. 31, Art. 32.

Ley de Arbitraje de 1995 (reformada el 2009): Art. 11, Art. 16, Art. 51.

Código de Conducta del 2005: Art. 2, Art. 7, Art. 9 , Art. 8, Art. 10.

CSP Opinión de 2009: Art. 12, Art. 13, Art. 16, Art. 22, Art. 23, Art. 24, Art. 25.

CSP Disposiciones de 2004: Art. 1, Art. 3 , Art. 7, Art. 8, Art. 13, Art. 15.

CSP Noticia de 2010: Art. 1.

Reglas de CIETAC del 2012: Art. 40.1, Art. 40.2 , Art. 40.3 , Art. 40.4 , Art. 40.5, Art. 40.6, Art. 40.8 